\title{
A Single Switch Parallel Quasi Resonant Converter Topology for Induction Heating Application
}

\author{
V. Geetha, V. Sivachidambaranathan \\ Sathyabama Institute of Science and Technology, Chennai, India
}

\begin{tabular}{|c|c|}
\hline Article Info & ABSTRACT \\
\hline Article history: & In this paper $32 \mathrm{KHZ}$ Single phase Single switch Parallel Resonant converter \\
\hline Received Apr 17, 2018 & $\begin{array}{l}\text { topology (SSPR) using power MOSFET is simulated using MATLAB } \\
\text { simulink for the different duty cycle and the THD Power with respect to }\end{array}$ \\
\hline Revised Aug 11, 2018 & change in duty cycle is compared . The workingcoil is the combination of $R$, \\
\hline Accepted Sep 12, 2018 & $\begin{array}{l}\mathrm{L} \text { in parallel with } \mathrm{C} \text { which produces the output power of } 1.7 \mathrm{KW} \text { to } 3 \mathrm{KW} \\
\text { with variation in duty cycle at higher value in duty cycle we get less } \mathrm{THD}\end{array}$ \\
\hline Keyword: & $\begin{array}{l}\text { and more power. The operating frequency is selected nearer to the resonant } \\
\text { frequency for the improvement performance. The experimental set up of this }\end{array}$ \\
\hline $\begin{array}{l}\text { Temperature } \\
\text { SSPR } \\
\text { THD }\end{array}$ & $\begin{array}{l}\text { SSPR Inverter in the induction heating application for the domestic purpose } \\
\text { is implemented is depicted and this validates the implementation of quasi } \\
\text { resonant using IGBT for domestic applications. }\end{array}$ \\
\hline
\end{tabular}

Copyright $(2018$ Institute of Advanced Engineering and Science. All rights reserved.

Corresponding Author:

V. Geetha,

Research Scholar,

Sathyabama Institute of Science and Technology,

Chennai 119.

Email: geethasendray28@gmail.com

\section{INTRODUCTION}

In the recent years the domestic purpose applications needs a clean environment, so people go for preferring electric based appliances rather using a fuel for cooking. after the analysis it is predicted that Induction Heating application provides a good performance in this automatic world. It basically works on the electromagnetic induction principle where the heat energy is dissipated in the form of eddy current or the hysteresis effect this magnetic hysteresis leads to joule effect from which the heat energy is utilized properly and effectively. This fast heating, cleanness, leads to the better usage of the induction heating system in the field of either domestic or medical. There are different inverter configuration available, basically the comparison of full bridge, half bridge, quasi and multi inverter are discussed in [1],[2] and concluded that a single switch inverter is best suited for domestic induction heating applications. Methodology used in this kind of application is the important factor in making the operation successful [3],[4] i.e., modulation technique used to trigger the switches in the circuit and duty ratio to be followed to have a better performance in the operation of the application [5],[6]. The performance of the system is compared with various switches like lower band gap switches and wide band gap switches followed in [7]-[9]. The arrangement of the working coil can be series, parallel, series parallel mostly the series arrangement is used for industrial purpose like melting, hardening, soldering, welding etc. ,parallel arrangement of the element in the coil can be made efficient for domestic application which has lower switching frequency and output power of range 0 to $2 \mathrm{kw}$ [10]. A full bridge series resonant topology is simulated to verify the steady state error, fall time, rise time, etc., in open loop and the same is been simulated with two different type of controllers such as PI, fuzzy and the results prove that fuzzy controller is best suited to have less time constrains [11] the multi inverter topology for induction heating application with less number of switches are discussed in [12],[13]. For multi burner operation in the field of induction heating is depicted in [14]-[16]. 
The above section discusses about the survey of the inverter part used in induction heating application in domestic section II discusses about the description of the proposed single switch parallel resonant topology and in section III various results of the proposed system is elaborated along with the simulation circuit section IV discusses the simulation results and section $\mathrm{V}$ the comparison table and section VI depicts experimental setup in section VII about the conclusive part.

\section{DESCRIPTION OF SINGLE PHASE SINGLE SWITCH PARALLEL RESONANT INVERTER}

The flow of operation of the domestic application is briefed using the following Figure 1. The usage of the change in switch and its performance based on duty cycle is depicted in this paper.



Figure 1. Method of Operation of SSPR Inverter

The proposed system explains the advantages of using the power MOSFET is only switch in place of the IGBT and the results of the system shows better performance and higher power and lesser THD for higher value of the duty cycle. The operating frequency is selected such that it is nearer to resonant frequency to reach the load needs. Here the working coil and the load are coupled magnetically and the eddy current flows through the coil to magnetise the work piece quickly, here the work piece taken is helical in nature specially meant for the domestic applications. The common power supply unit for any kind of induction heating application is always the series connected load but parallel connected load also gives good results compared to the series or series parallel.

The circuit description of the proposed system is shown in Figure 2. The utility frequency AC supply is converted to the high frequency AC supply in the double stage operation with the use of a bridged rectifier which converts the AC supply to the DC supply which acts as the input to the single switch resonant inverter providing a high frequency AC output collected across the parallel connected resonant tank circuit which acts a working coil and produces a required power for driving a inductive load.

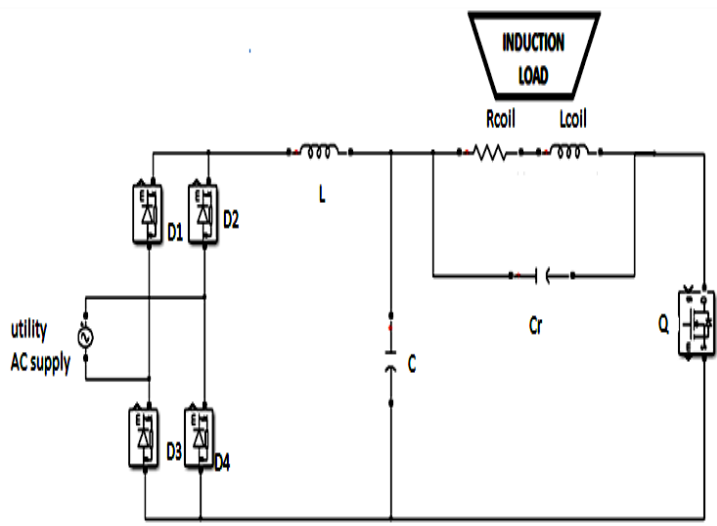

Figure 2. Single switch parallel resonat converter

\section{SIMULATION OF SINGLE SWITCH PARALLEL RESONANT NVERTER}


The simulation of the proposed single switch parallel resonant inverter circuit is carried out at a operating frequency of $32 \mathrm{KHz}$ for different duty cycle and the Simulation circuit is depicted in Figure 3. The conventional system and the proposed system is simulated for different switching frequency and the frequency nearer to resonant frequency is chosen to be a operating frequency and those results are also depicted in the following figure and the comparison of the conventional and the proposed is done the proposed system is validating the results for various duty cycle.

The proposed system is simulated for the different duty cycle and the results are compared for THD and power. The simulation circuit of the proposed system is shown in Figure 3. The operation of the circuit is explained as follows, at the initial stage the switch $\mathrm{M}$ is on and the coil carries a voltage of input and after certain period of time the switch moves to the off state and the capacitor parallel to the coil proceed the operation with its voltage and now the current and the voltage through the coil is reversed for next set of operation. Thus the output is converted to the high frequency AC voltage to drive the coil and from which the work piece is magnetised and the required heat is generated for the application. This operation is repeated for various duty cycle and results are depicted.

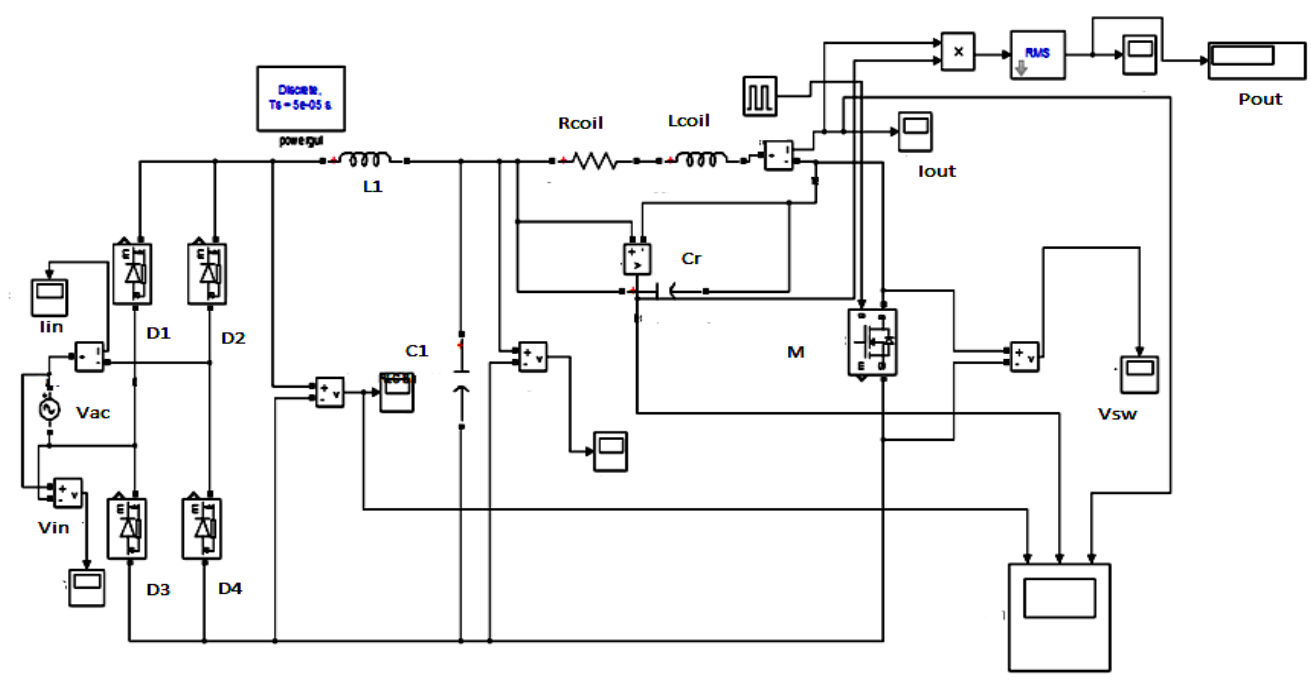

Figure 3. Simulation Of the proposed single switch parallel resonant inverter

The simulation circuit depicted explains about the measured quantities for a single switch parallel resonant inverter for a single switching frequency and various duty cycle for the same load. the various output waveforms for the $32 \mathrm{KHZ}$ switching frequency is depicted in Figure 4.
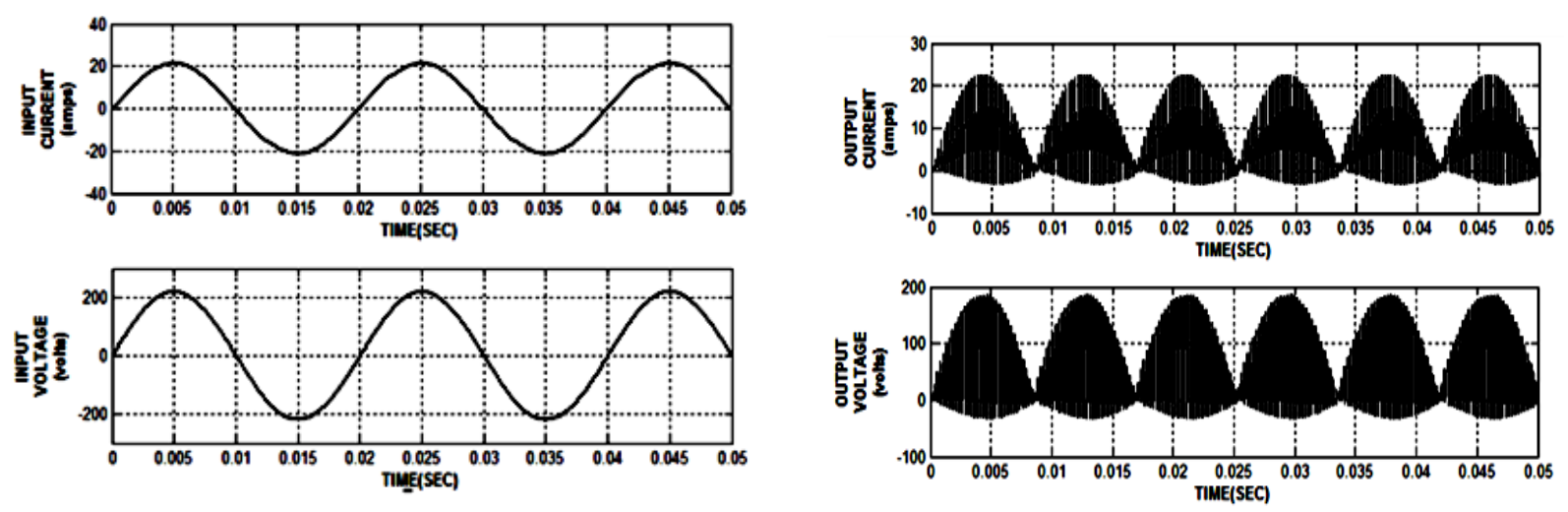

Figure 4 (a) $\mathrm{V}_{\text {IN }}$ and $\mathrm{I}_{\mathrm{IN}}$ of proposed single switch parallel resonant inverter for $32 \mathrm{KHZ}$ operating frequency

Figure 4(b) $\mathrm{V}_{\text {out }}$ and $\mathrm{I}_{\text {out }}$ of proposed single switch parallel resonant inverter for $32 \mathrm{khz}$ operating frequency

\section{SIMULATION RESULTS OF THE PROPOSED CONVERTER}


The simulation of the proposed system is carried out for different duty cycle and the results are depicted in this section



Figure 5. FFT Analysis proposed single switch parallel resonant inverter for $50 \%$ duty cycle

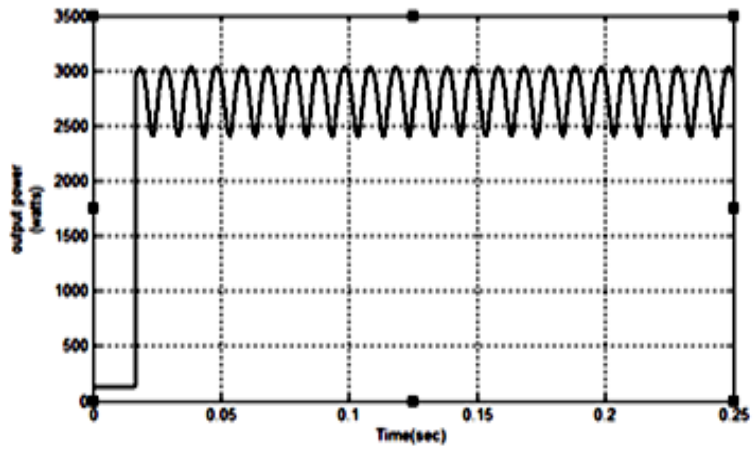

Figure 6. Output power of proposed single switch parallel resonant inverter with $50 \%$ duty cycle

The power developed in the proposed system for $50 \%$ of duty cycle is $3.013 \mathrm{KW}$ Total Harmonic Distortion value was found to be $124.18 \%$.

The power developed in the proposed system for $70 \%$ duty cycle is $3.105 \mathrm{KW}$ and it is viewed in Figure 8 using MATLAB. Total Harmonic Distortion value was found to be $110.06 \%$ is clear in Figure 7 . The same simulation is repeated for $90 \%$ duty cycle, the following Figures 9 and 10 depicting the output power and THD as $3.125 \mathrm{KW}$ and $108.09 \%$ the results of the proposed system depicts the variation in the power and THD .



Figure 7. FFT Analysis proposed single switch parallel resonant inverter for $70 \%$ duty cycle

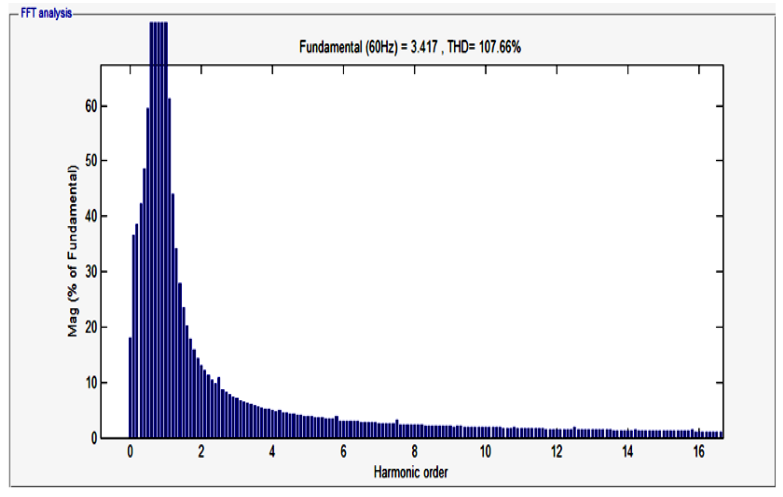

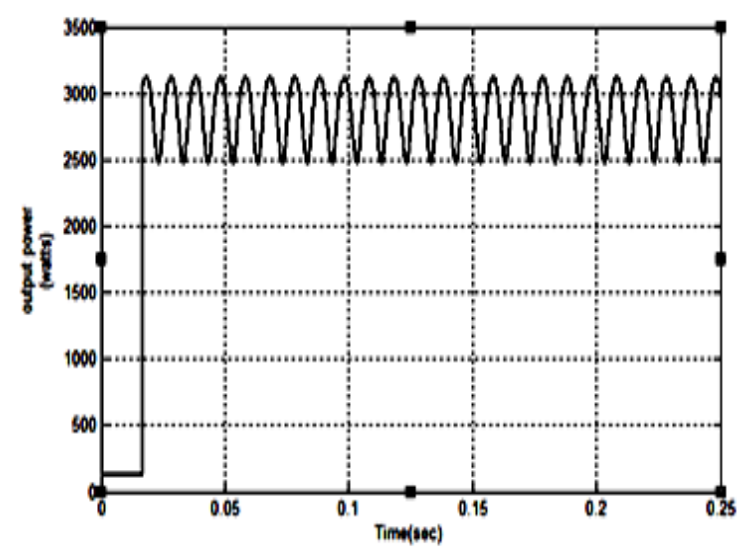

Figure 8. Output power of proposed single switch parallel resonant inverter with $70 \%$ duty cycle

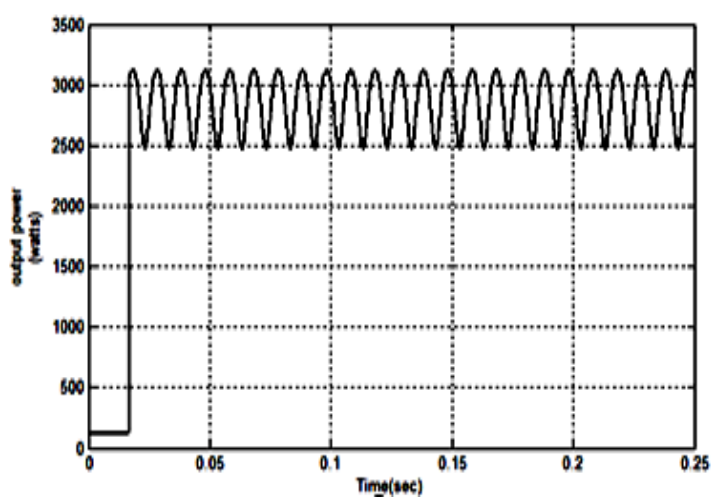


Figure 9. FFT Analysis proposed single switch parallel resonant inverter for $90 \%$ duty cycle
Figure 10. Output power of proposed single switch parallel resonant inverter with $90 \%$ duty cycle

The total harmonic distortion of the circuit is calculated either by power ratio nor voltage ratio or by current ratio. Ratio between the power of all harmonics to the fundamental power.Distortion level can also be measured with the voltage ratio and also current ratio.

$$
\mathrm{THD}=\left(\mathrm{P}_{\text {total }}-\mathrm{P}_{1}\right) / \mathrm{P}_{1}
$$

\section{COMPARISON OF RESULTS}

The various results of the systems are compared and clarified and they are tabulated as follows validating the system performance. Table 1 depicts the comparison between the various parameters with different switches MOSFET and the IGBT and proves that usage of the switch MOSFET gives a better result compared to IGBT for which with the same load parameters and change in the duty cycle simulation is repeated to check for improvement in the proposed system and compares the result of the proposed system with change in duty cycle.

The comparison chart is drawn to have a clear idea in the performance of the system viewed in Figure 11 and 12. The chart which explains the performance of the SSPR with duty cycle and this chart enable to know the performance.

Table 1. Comparison Table for Mosfet and IGBT

\begin{tabular}{|c|c|c|c|}
\hline \multicolumn{2}{|c|}{ PARAMETEER } & IGBT & MOSFET \\
\hline \multicolumn{2}{|c|}{$\mathrm{I}_{\mathrm{IN}}(\mathrm{Amp})$} & 20 & 20 \\
\hline \multicolumn{2}{|c|}{$\mathrm{V}_{\text {IN }}$ (Volts) } & 220 & 220 \\
\hline \multicolumn{2}{|c|}{ I OUT (Amps) } & 18 & 22 \\
\hline \multicolumn{2}{|c|}{ V out(Volts) } & 180 & 220 \\
\hline & $50 \%$ & 127.90 & 124.18 \\
\hline \multirow[t]{2}{*}{ THD\% } & $70 \%$ & 129.80 & 110.66 \\
\hline & $90 \%$ & 108.09 & 107.69 \\
\hline \multirow{3}{*}{$\mathrm{P}_{\text {OUT }}(\mathrm{KW})$} & $50 \%$ & 1.765 & 3.034 \\
\hline & $70 \%$ & 2.724 & 3.105 \\
\hline & $90 \%$ & 3.094 & 3.124 \\
\hline
\end{tabular}

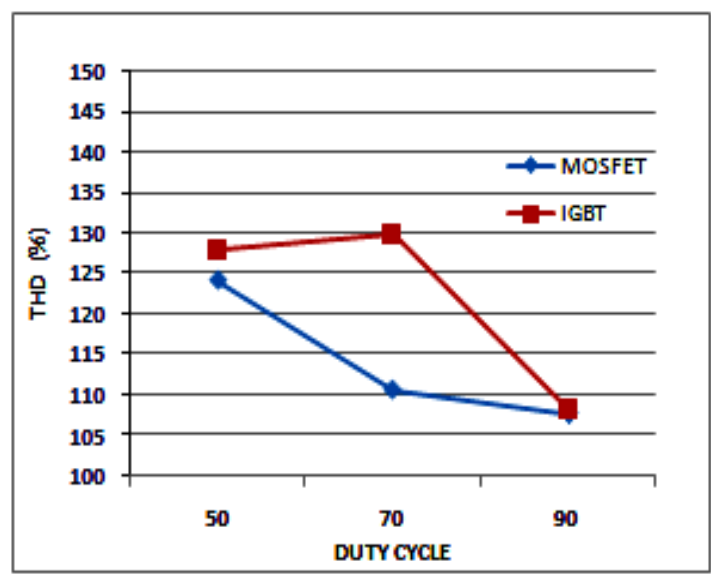

Figure 11. Duty cycle VS THD\%

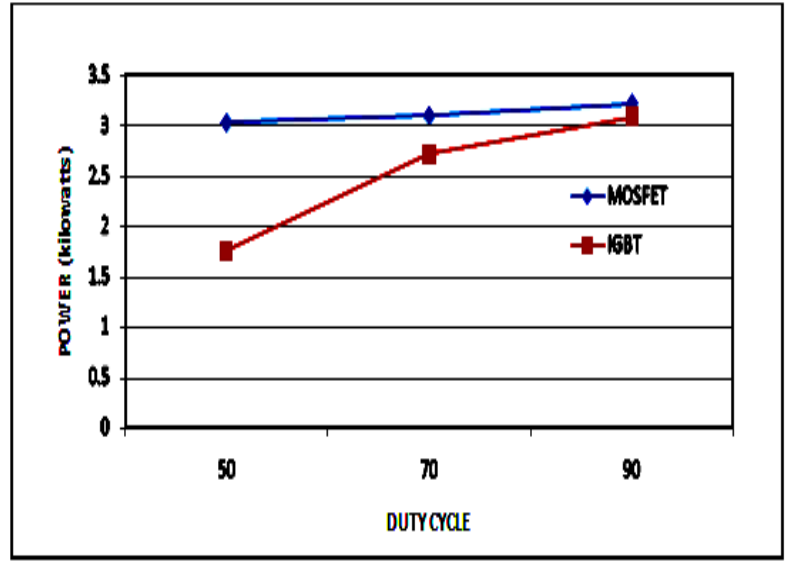

Figure 12. Duty cycle VS Power (KW)

\section{EXPERIMENTAL SET UP}

The prototype of the single switch parallel quasi resonant converter is implemented and the setup is depicted in the following image which provided the knowledge of electromagnetic induction and the excitation of the coil with load and without excitation is shown in Figure 13 and 14 respectively.after the analysis and implementation a future work of half bridge inverter with parallel resonant load can be 
implemented and the results can be compared to satisfy the essential criteria for the induction heating principle.the output of th hardware prototype depicts the joule effect and the heat transferred to the working medium without any contact and heat produced by this effect is utilized by the load only not on the work piece.

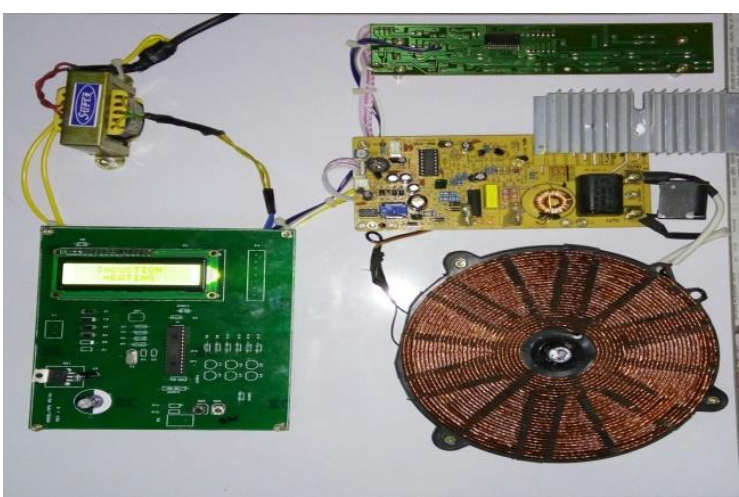

Figure 13. Hardware set up of the prototype without excitation

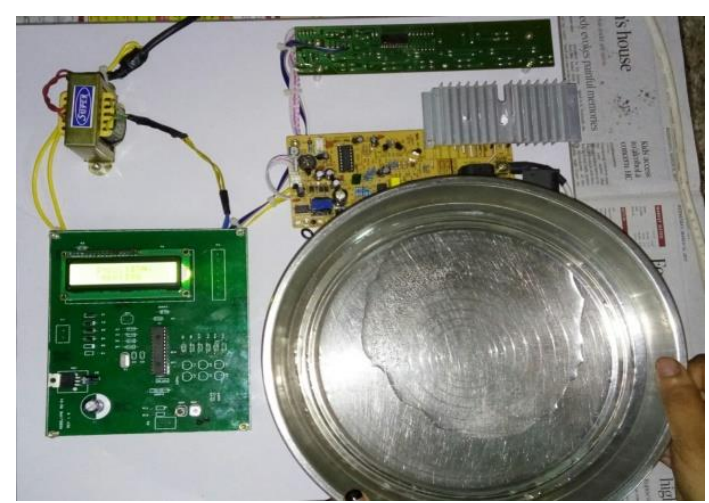

Figure 14. Hardware set up of the prototype with excitation

\section{CONCLUSION}

The paper expresses about the simulation and the experimental setup of the single phase single switch parallel resonant inverter for domestic applications it is proved by simulation that at higher duty cycle the power generated is more and the experimental set up is made for $32 \mathrm{khz}$ operating frequency thus concluding that property of the MOSFET and IGBT is studied having lesser so that the system developed is suited for all kinds of domestic induction heating application.

\section{REFERENCES}

[1] O. Lucía, et al., "Induction Heating Technology And Its Applications,Past Developments, Current Technology, and Future Challenges," IEEE Transactions On Industrial Electronics, vol/issue: 61(5), 2014.

[2] H. Sarnago, et al., "Class-D/DE dual-mode-operation resonant converter for improved-efficiency domestic induction heating system," IEEE Trans. Power Electron., vol/issue: 28(3), pp. 1274-1285, 2013.

[3] K. Selvamuthukumar, et al., "Single phase thirteen level inverter with reduced number of switches using different modulation techniques," ARPN Journal of Engineering and Applied Sciences, vol/issue: 10(22), pp. 10455-10462, 2015.

[4] H. W. Koertzen, et al., "A comparative study of single switch induction heating converters using novel component ef- fectivity concepts," IEEE PESC, pp. 298-305, 1992.

[5] M. Kavitha and V. Sivachidambaranathan, "Transformerless Inverter using Unipolar Sinusoidal Pulse Width Modulation Technique for Grid Connected Photovoltaic Power System," International Journal of Applied Engineering Research, vol/issue: 10(2), pp. 3089-3100, 2015.

[6] V. Sivachidambaranathan, "Bi-Directional Series Parallel Resonant Converter For Power Factor Correction," International Journal of Applied Engineering Research, vol/issue: 9(21), 2014.

[7] P. K. Sadhu, et al., "Selection of Power Semiconductor Switches in M.H.B.R.I. Fitted Induction Heater for Less Harmonic Injection in Power Line," International Journal of Power Electronics and Drive System, vol/issue: 6(1), pp. 121-128, 2015.

[8] H. Sarnago, et al., "Direct ac-ac resonant boost converter for efficient domestic induction heating applications," IEEE Trans. Power Electron., 2014.

[9] H. Sarnago, et al., "High efficiency parallel quasi-resonant current source inverter featuring SiC MOSFETs for induction heating systems with coupled inductors," IET Power Elec- tron., vol/issue: 6(1), pp. 183-191, 2013.

[10] S. Chudjuarjeen and C. Koompai, "A High-Frequency Induction Cooker using Qusai-resonant Converter," ECTIConf., pp. 378-381, 2007.

[11] K. Sahiti and V. Geetha, "Simulation of series resonant inverter using pulse density modulation," ARPN journal of engineering and applied sciences, vol/issue: 10(7), 2015.

[12] A. R. Babu, "Comparative analysis of cascaded multilevel inverter for phase disposition and phase shift carrier PWM for different load," Indian Journal of Science and Technology, vol/issue: 8(S7), pp. 251-262, 2015.

[13] B. Saha and R. Y. Kim, "High Power Density Series Resonant Inverter Using an Auxiliary Switched Capacitor Cell for Induction Heating Applications," IEEE Transactions on Power Electronics, vol/issue: 29(4), pp. 1-3, 2014. 
[14] M. Saravanan and A. R. Babu, "High Power Density Multi MOSFET based series resonant inverter for Induction Heating Applications," International Journal Of Power Electronics and Drive System, vol/issue: 7(1), pp. 107-113, 2016.

[15] O. Lucía, et al., "Multiple-output resonant matrix converter for multiple induction heaters," IEEE Trans. Ind. Appl., vol/issue: 48(4), pp. 1387-1396, 2012.

[16] V. Sivachidambaranathan, "High frequency isolated series parallel resonant converter," Indian Journal of Science and technology, 2015. 